\title{
Does Posture Influence the Stroop Effect?
}

\author{
by \\ Emilie Caron

\begin{abstract}
A thesis
presented to the University of Waterloo

in fulfilment of the

thesis requirement for the degree of

Master of Arts

in

Psychology
\end{abstract}

Waterloo, Ontario, Canada, 2019

(C) Emilie Caron 2019 


\section{Author's Declaration}

This thesis consists of material all of which I authored or co-authored: see Statement of Contributions included in the thesis. This is a true copy of the thesis, including any required final revisions, as accepted by my examiners.

I understand that my thesis may be made electronically available to the public. 


\section{Statement of Contributions}

What is presented here are two studies from a recently submitted paper that also included two additional studies conducted by collaborators at Trent University (also described in the General discussion of this thesis). I contributed to the study design and the development of the computer versions of the Stroop task in collaboration with Dr. Michael Reynolds, Dr. Brandon Ralph, Dr. Jonathan Carriere, and Dr. Daniel Smilek. Additionally, I performed the testing, data collection and

data analysis in collaboration with Dr. Michael Reynolds and Dr. Jonathan Carriere. Initial drafts of the thesis were composed primarily by myself, and Dr. Daniel Smilek. All authors approved the final version of the thesis for submission. 


\begin{abstract}
Rosenbaum, Mama, and Algom (2017, Psychological Science, 28, 1864-1867) reported that participants completing the Stroop task (i.e., name the hue of a colour word when the hue and word meaning are congruent or incongruent), showed a smaller Stroop effect (i.e., the difference in response times (RT) between congruent and incongruent trials) when they completed the task standing than when sitting. Here, we report two attempted replications of Rosenbaum et al.'s findings. In Experiment 1 we replicated Rosenbaum et al.'s methodology while also including neutral trials to evaluate whether posture affected Stroop interference (by comparing incongruent and neutral trials) and/or Stroop facilitation (by comparing congruent and neutral trials). In Experiment 2 participants completed only congruent and incongruent trials but were also instructed to keep their feet flat on the floor approximately hip-width apart and avoid leaning on the desk. Because Rosenbaum et al. proposed that standing is attentionally demanding and consumes resources needed for the Stroop task, we hoped that having participants focus on their posture in Experiments 2 might, if anything, increase our chances of replicating Rosenbaum et al.'s findings. Results from both experiments yielded the standard Stroop effect (i.e., slower RTs on incongruent vs. congruent trials (and neutral trials in Experiment 1)), but we failed to detect any influence of posture (sitting vs. standing) on the magnitude of the Stroop effect. Taken together, the results suggest that posture does not influence the magnitude of the Stroop effect to the extent that was previously suggested.

Keywords: Active workstations, standing desks, cognitive function, selective attention, Stroop task
\end{abstract}




\section{Acknowledgements}

This research was supported by Discovery grants from the Natural Sciences and Engineering Research Council (NSERC) of Canada awarded to Dr. Daniel Smilek and Dr. Jonathan Carriere. This research was also supported by a graduate scholarship from the Fonds de recherche Nature et Technologies de Québec (FRQNT) that I received in support of completing my Master's research. I would like to thank my supervisors, Dr. Daniel Smilek and Dr. Jonathan Carriere for their support, encouragement, and guidance throughout the completion of my Master's thesis.

Additionally, I would like to thank my readers, Dr. Jonathan Fugelsang and Dr. Mike Dixon for their time and valuable comments and suggestions on improving my thesis.

I would also like to thank Dr. Brandon Ralph, Dr. Michael Reynolds, Dr. Derek Besner and Daev McLean for their mentorship and enthusiasm throughout the experimental process.

Last, but certainly not least, I would like to thank my research assistants, Abby Postma, Shaveta Gupta, Thiviya Subramaniam, Leila Stube, and Samantha Marshall, who helped with participant testing and data collection. 


\section{Dedication}

This thesis is dedicated to my family, partner (MG) and closest friends (AS, ED-L and AW). Their patience, encouragement and unwavering confidence in my abilities have helped me to stay focused on and committed to successfully achieving my goals. 


\section{Table of Contents}

Author's

Declaration

Statements of

iii

Contribution

Abstract

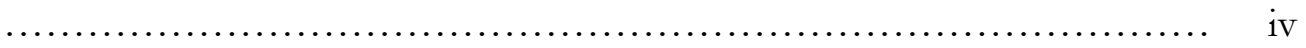

Acknowledgements

V

Dedication

$\cdots$

vi

List of Figures

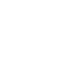

vi

List of Tables

$$
\cdots
$$

Quotes

$\cdots$

Current Study

$$
\cdots
$$

Introduction

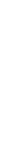

Experiment 1

Method

Results

Discussion

Experiment 2

Method

Results

Discussion

General

Discussion

References 
Appendix A. Mean response times and percentage error from Experiment 1 as a function of Posture (Sitting vs. Standing), Congruency (Incongruent, Neutral, Congruent) and Block Number (1 vs. 2).

Appendix B. Experiment 1 Additional analyses examining the full design including Posture (Sitting vs. Standing), Congruency (Incongruent, Neutral, Congruent) and Counterbalance (Sitting first vs. Standing first) a within-subject factors within the ANOVA.

Appendix C. Mean response times and percentage error from Experiment 2 as a function of Posture (Sitting vs. Standing), Congruency (Incongruent, Neutral, Congruent) and Block Number (1 vs. 2).

Appendix D. Experiment 2 Additional analyses examining the full design including Posture (Sitting vs. Standing), Congruency (Incongruent, Neutral, Congruent) and Counterbalance (Sitting first vs. Standing first) a within-subject factors within the ANOVA.

Appendix E. Mean Response Time and Mean Percentage Error as a Function of Posture and Congruency from Experiment 1 conducted at Trent University

Appendix F. Mean Response Time and Mean Percentage Error as a Function of Posture and Congruency from Experiment 2 conducted at Trent University 


\section{List of Figures}

Figure 1. Mean RT and PE as a function of Posture and Congruency from Experiment 1.......

Figure 2. Mean RT and PE as a function of Posture and Congruency from Experiment 2. ......

Figure 3. Mean RT and PE as a function of Posture and Congruency from Trent Experiment

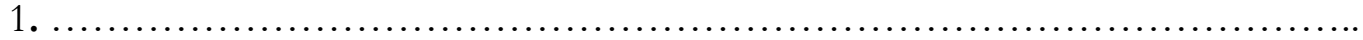
44

Figure 4. Mean RT and PE as a function of Posture and Congruency from Trent Experiment

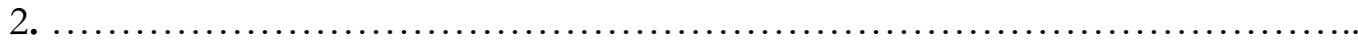




\section{List of Tables}

Table 1. Analysis of the four experiments reported in the present paper and the three experiments reported by Rosenbaum et al. (2017) using a robust mixed model ANOVA with $20 \%$ Windsorized means.

Table 2. Mean response times and percentage error from Experiment 1 as a function of Posture (Sitting vs. Standing), Congruency (Incongruent, Congruent) and Block Number (1 vs. 2).

Table 3. Mean response times and percentage error from Experiment 2 as a function of Posture (Sitting vs. Standing), Congruency (Incongruent, Congruent) and Block Number (1 vs. 2). 


\section{Quotes}

"Reproducibility is the hallmark of credible scientific evidence"

"Part of the problem [with conducting replications] is the lack of prestige associated with carrying out replications (Smith,1970). To put simply, few would want to be seen by their peers as merely "copying" another's work (e.g., Mulkay and Gilbert, 1986); and few could afford to be seen in this way by tenure committees or by the funding bodies that sponsor their research. Thus, while "a field that replicates its work is [seen as] rigorous and scientifically sound" - according to Makel et al. (2012) - psychologist who actually conduct those replications "are looked down on as bricklayers and not [as] advancing [scientific] knowledge” (p.537). In consequence, actual replication attempts are rare." 


\section{Introduction}

There is accumulating evidence that excessive sitting in daily life is associated with poor health outcomes (van Uffelen et al., 2010; Proper, Singh, Van Mechelen, \& Chinapaw, 2011; van der Ploeg Chey, Korda, Banks, \& Bauman, 2012; Ekelund et al. 2016). For example, a large study (involving over 200,000 adults) has shown that long sitting times are associated with higher all-cause mortality even when a whole host of other mortality-related factors (e.g., sex, age, BMI, urban/rural residence) - including physical activity - are statistically controlled (van der Ploeg et al., 2012). Fortunately, the evidence also suggests that "[high] levels of moderate intensity physical activity (i.e., about 60-75 min per day) seem to eliminate the increased risk of death associated with high sitting time." (Ekelund et al., 2016, p. 1302). Intriguingly, some have suggested that health can be improved to some extent simply by introducing active workstations (such as standing desks and treadmills) in the workplace (e.g., MacEwen, MacDonald \& Burr, 2015; Torbeyns, Bailey, Bos \& Meesuen, 2014). Given the apparent negative effects of sitting, and the possible positive effects of physical activity and active (e.g., standing) workstations on overall health, researchers have begun to examine how common postures such as sitting and standing relate to psychological factors such as brain health (e.g., Voss, Carr, Clark \& Weng, 2014), work productivity (Chau et al. 2016; see also Garrett et al. 2016), as well as cognitive performance (Bantoft et al. 2016; Ebara et al., 2008; Russell et al. 2016).

Our interest in the potential influence of posture (sitting versus standing) on cognitive performance was triggered by a recent series of studies reported by Rosenbaum, Mama, and Algom, (2017) in the Journal of Psychological Science. The authors documented a seemingly compelling demonstration of how performance on a cognitive task is influenced by a person's posture (sitting vs. standing). In these studies, participants completed a Stroop task (Stroop, 1935), in which they were required to name the hue of colour-words whose meaning either matched (congruent trials) or mismatched (incongruent trials) the hue. Readers are typically slower to name the colour of the stimuli 
on incongruent trials than on congruent trials (commonly referred to as the Stroop effect), which is commonly believed to be because word reading is "automatic" and interferes with colour naming on incongruent trials, and/or facilitates colour naming on congruent trials (Rayner \& Pollatsek, 1989; Ashcraft, 1994). Critically, in several studies, Rosenbaum et al. found that the Stroop effect was smaller when participants completed the task when standing compared to when sitting. Rosenbaum et al. argued that standing reduces the magnitude of the Stroop effect because the added requirement of controlling postural muscles while standing (relative to sitting), increases cognitive load, thus reducing the amount of available resources for processing the distracting word meaning. They hypothesize this to be the reason the main movement in response time across sit and stand conditions was observed primarily on incongruent trials.

Rosenbaum et al.'s (2017) finding — that posture can influence the magnitude of the Stroop effect-is interesting for several reasons. First, reports addressing this issue that predate Rosenbaum et al.'s report suggest that there is no compelling influence of posture on Stroop performance (Bantoft et al., 2016; Russell et al., 2016; Patston, Henry, McEwen, Mannion \& Ewens-Volynkina, 2017; Schraefel, Jay, \& Anderson, 2012). That said, these prior studies generally lacked the clear and direct assessment of performance on both congruent and incongruent trials and a direct comparison of the magnitude of the Stroop effect across sit and stand conditions as conducted by Rosenbaum et al.. For instance, Russell et al. (2016) had participants complete the Stroop task (in addition to several other cognitive tasks) while using active workstations in either the sitting or standing positions. The authors claim that posture did not influence performance on the Stroop task. While this conclusion might seem inconsistent with Rosenbaum et al.'s conclusion, it is important to note that Russel et al. only assessed performance on incongruent trials of the Stroop task, whereas Rosenbaum et al. assessed performance on both incongruent and congruent trials. Thus, given Russel et al.'s design, they were unable to speak to the influence of posture on the magnitude of the Stroop effect, which is indexed 
as the difference in RTs between incongruent and congruent (or neutral) trials (as was done by Rosenbaum et al.).

Another example of a study in which the effects of posture on Stroop performance were assessed is a study conducted by Bantoft et al. (2016). In their study participants partook in three separate laboratory sessions scheduled a week apart from each other. Each laboratory session consisted of participants completing several cognitive tasks (including the Stroop task) in different assigned positions (e.g., sitting, standing, and walking on a treadmill) at an adjustable active workstation. The authors reported that participants named the colour of incongruent and neutral trials. By including both incongruent and neutral trials within their study, Bantoft et al. would have been able to measure the magnitude of the Stroop effect by measuring the difference in RTs between incongruent and neutral trials. Unfortunately, the authors did not report the magnitude of the Stroop effect, opting only to report the RTs on the incongruent trials. The results showed that posture did not influence performance on incongruent trials. While again this might seem to be inconsistent with the findings of Rosenbum et al., it is difficult to make a direct comparison across studies because, as noted, Bantoft et al. did not report the magnitude of the Stroop effect. Nevertheless, given that Rosenbaum et al. reported that posture influenced primarily performance on incongruent trials, one might have expected to see an effect of posture on incongruent trial performance, but this was also not found in prior studies. Given this state of affairs, it seems prudent to conduct a replication of Rosenbaum et al.'s study in order to confirm their findings.

We also found the results presented by Rosenbaum et al. (2017) to be interesting because of their theoretical implications. Specifically, the modulation of the magnitude of the Stroop effect by changes in posture suggests that word reading is contextually influenced (e.g., Labuschagne \& Besner, 2015; Besner et al., 2016) rather than "automatic" as widely claimed (Rayner \& Pollatsek, 1989; Ashcraft, 1994). More specifically, the standard Stroop effect is commonly believed to reflect the 
automaticity of word reading, a process which is assumed to occur extremely quickly, effortlessly, without intention, without the individual's conscious awareness (Kuhn, Schwanenflugel, Meisinger, Levy \& Rasinski, 2010; Logan, 1997) and, critically, independent of the context in which words appear (Labuschagne \& Besner, 2015). Some have argued however, that word reading is not automatic based on demonstrations that the magnitude of the Stroop effect depends on the specific context in which the words are presented (Labuschagne \& Besner, 2015). For example, Labuschagne and Besner showed that the magnitude of the semantic version of the Stroop effect (in which the word is semantically related to a colour) can be substantively reduced (and even eliminated) if only a single letter of the word is coloured and this letter is preceded by a spatial cue that directs attention to the letter, with this sort of stimulus configuration being present in a blocked design relative to other stimulus configurations (e.g., all letters coloured and spatially cued). This dependence of the magnitude of the Stroop effect on contextual (stimulus presentation) factors suggests that word reading is not automatic — after all, in Labushchange and Besner's studies, the words were always in plain view, but their influence on colour naming depended on contextual factors. Along similar lines, the modulation of the Stroop effect by posture, as reported by Rosenbaum et al., provides further support for the general notion that word reading is not automatic, but is contextually driven (Besner et al., 2016; Besner \& Reynolds, 2017; Labuschagne \& Besner, 2015; White \& Besner, 2018).

Another reason that we found Rosenbaum et al.'s findings interesting involves the general implication of their findings, which is that the state of one's body (i.e., posture) influences basic cognitive processing; an implication that is consistent with embodied views of cognition (Barsalou, 2008; Matheson, \& Barsalou, 2018; Wilson, \& Foglia, 2011; Winkielman, Niedenthal, Wielgosz, Eelen, \& Kavanagh, 2015; Shapiro, 2010). In general, embodied views of cognition are based on the notion that the cognitive system cannot be properly understood if it is separated from the body and the environment in which the system is embedded and operating (Matheson, \& Barsalou, 2018). One 
specific hypothesis within the embodied framework is that cognitive processes are influenced by the state of the body—what Shapiro (2010) calls the influence bypothesis. Because robust instances of the influence hypothesis are hard to come by (Cooper, Sterling, Bacon \& Bridgeman, 2012; Oberman, Winkielman, \& Ramachandran, 2007; Witt, Proffit \& Epstein, 2004; Witt, Proffit \& Epstein, 2005; Witt, 2011; ) we found value in Rosenbaum et al.'s findings as they seem to provide a strong and definitive example of this hypothesis.

Finally, we noticed that there is one aspect of Rosenbaum et al.'s (2017) findings that does not seem to fully comport with their theoretical explanation. Rosenbaum et al. found that posture primarily influenced performance on incongruent trials and not on congruent trials. However, their theoretical point of view (that posture influences cognitive load, which influences processing of word meaning) would also suggest that compared to sitting, standing ought to reduce Stroop facilitation on congruent trials, an effect that Rosenbaum et al. did not find. While this could be explained by positing that Stroop facilitation (i.e., the performance difference between neutral and congruent trials), simply did not occur in Rosenbaum et al.'s studies (and so it could not be influenced by a change in posture), at present it is difficult to reach a strong conclusion because proper assessment of Stroop facilitation (and interference - the performance difference between neutral and incongruent trials - for that matter), would require the inclusion of neutral baseline trials, which were absent from Rosenbaum et al.’s design.

Against this backdrop we sought to build on the prior work examining the impact of posture (Sitting vs. Standing) on performance on the Stroop task. In what follows we report two experiments aimed at replicating and extending the findings reported by Rosenbaum et al (2017). In our first experiment, we conducted a close replication of Rosenbaum et al.'s studies with two research goals in mind. The first was to determine whether we could replicate the findings obtained by Rosenbaum et al.. The second goal was to determine exactly how posture influences performance on the Stroop task 
- does this influence of posture manifest as an influence on Stroop interference (as suggested by Rosenbaum et al.) or facilitation or both? In order to determine the influence of posture on Stroop performance, we included neutral trials in our experimental design. If posture influences performance on Stroop facilitation, then it would indicate that standing compared to sitting slows participants' ability to accurately respond to the colour words by increasing the saliency of the distractor words. On the other hand, if posture influences interference on the Stroop task than it would mean that standing enhances participants' ability to accurately respond to the colour words by decreasing the saliency of the distractor words.

To anticipate the outcome of the first study, we failed to find an influence of posture (Sitting vs. Standing) on either Stroop facilitation or interference, which amounts to a failure in replication of Rosenbaum et al.'s study. However, it is worth noting that our methodology differed from that of Rosenbaum et al.'s with regard to the inclusion of neutral trials. In addition, we did not, in our first experiment, carefully instruct people not to lean on the desk. This might be problematic because leaning on the desk would reduce postural demands in the standing condition, and this might have undermined the effectiveness of the sit vs. stand manipulation. Given these considerations, in our second experiment we attempted a replication that more closely resembled Rosenbaum et al.'s studies by removing the neutral trials from the design. In addition, in the second experiment we included instructions regarding the maintenance of posture throughout the task. In both sit and stand conditions, participants were instructed to keep their feet flat on the floor approximately hip-width apart and to avoid putting their hands on the desk, as well as to avoid leaning on the desk. To anticipate once more, consistent with the results of Experiment 1, in Experiment 2 we again failed to find a modulation of the magnitude of the Stroop effect by posture. 


\section{Experiment 1}

The aims of Experiment 1 were two-fold. Our first aim was to closely replicate Rosenbaum et al.'s (2017) studies, which we felt was important in light of prior studies that have failed to accurately compare performance on congruent and incongruent trials via the Stroop task. An equally important second aim was to evaluate whether the impact of posture - should one be forthcoming - would specifically manifest as an influence on Stroop interference or facilitation, or both. While Rosenbaum et al. concluded that posture exerts its influence by modulating interference on incongruent trials in the Stroop task, they did not include neutral trials, which are required to decisively evaluate their claim. Specifically, an effect of posture on interference would manifest as an influence on the magnitude of the performance difference between neutral and incongruent trials, while an effect of posture on facilitation would manifest as an influence on the magnitude of the difference between neutral and congruent trials. Based on these considerations, in Experiment 1 participants completed a Stroop task while sitting and while standing. The Stroop task included congruent and incongruent trials (following Rosenbaum et al.) as well as neutral trials (not included by Rosenbaum et al.) so that the effects of posture on interference (incongruent trials) and facilitation (congruent trials) could be clearly distinguished.

\section{Method}

Participants. In advance of the study we decided to double the sample size of Rosenbaum et al.'s (2017) Experiment 3. Therefore, 122 University of Waterloo undergraduates participated in a 30min study for course credits.

Stimuli. There were three different types of stimuli: Congruent, Incongruent and Neutral. The Congruent stimuli consisted of the words "RED" presented in the colour red (RGB 150, 0, 0), "GREEN" presented in the colour green (RGB: 27, 111, 27), "BLUE” presented in the colour blue

(RGB: 0, 0, 150), and "BROWN" presented in the colour brown (RGB: 68, 47, 41). The Incongruent 
stimuli included all other combinations of the colour words and hues. The neutral stimuli consisted of coloured strings of three to five Xs matched to the number of letters in the four colour words. The stimuli were displayed in uppercase Miriam 78 pt. font, on a light grey (RGB: 122, 122, 122) background.

Apparatus. The experiment was programmed using Pygame 1.9.3 in the Python 2.7.14 programming software and run on a desktop PC. Stimuli were presented on a Dell 2007 WFP monitor with the display resolution set to $1680 \times 1050$ True colour (32 bit) at 59Hz. The computer and monitor were placed an Ikea BEKANT desk (https://www.ikea.com/ca/en/catalog/products/S29022520/), which was electrically adjusted in height to accommodate the height of the participants in both conditions so that the position of the arms and head approximated accepted ergonomic guidelines (Canadian Centre for Occupational Health and Safety, 2019). In the sitting condition, participants sat on a chair. The computer monitor was adjusted so that the center of the screen was at eye level for participants. Vocal responses were collected using a noise-cancelling Plantronics Audio microphone (Model 326; https://www.plantronics.com/ca/en/support/product/au dio-326).

Procedure. The experiment consisted of 1 block of 48 practice trials followed by 2 blocks of 108 experimental trials. One experimental block was performed sitting and the other standing. The order of posture condition was counterbalanced across participants (see Appendix A and B for a table and additional analyses including counterbalance as a within-subject factor). The experimental trials included 36 trials of each of the Congruent, Incongruent and Neutral conditions, with nine repetitions of each hue in a given condition. On each trial participants were asked to respond "as quickly and accurately as possible" to the hue while ignoring the meaning of the letter string. On each trial, the letter string appeared for $2000 \mathrm{~ms}$ (regardless of response time), after which it was replaced by a grey screen for $2000 \mathrm{~ms}$. At the end of the experiment participants were asked whether they preferred 
sitting or standing while completing the task, however this data was considered exploratory and not analyzed for the present report.

\section{Results}

$R$ statistical software (version 3.4.3) was used to analyze the data. The response time (RT) and Percentage Error (PE) data (see Figure 1) were analyzed separately using a repeated measures Analysis of Variance (ANOVA) with Posture (Sitting vs. Standing) and Congruency (Neutral vs. Congruent vs. Incongruent) as within-subject factors. Prior to analyzing the RT and PE data, 14 participants were excluded from the analysis due to high levels of missing data $(>20 \%)$ arising from a failure to record vocal responses. For the remaining 108 participants, 2.09\% of the data was removed due to hardware failures. The RT data were analyzed using only correct responses resulting in the removal of an additional $0.81 \%$ of the data. An additional $0.24 \%$ of the correct RT data were excluded due to premature triggering of the voice key $\left(<=205 \mathrm{~ms}^{1}\right)$. The remaining correct RT data was submitted to a recursive data trimming procedure in which the criterion for outlier removal is calculated separately for each participant in each cell based on sample size (Van Selst \& Jolicoeur, 1994) ${ }^{2}$. This resulted in the removal of $1.26 \%$ of the data.

RTs. There was a significant main effect of Posture, $F(1,107)=18.94, M S_{\text {error }}=3947.61, p<$ $.001, \eta_{p}{ }^{2}=0.150$. There was also a main effect of Congruency, $F(2,214)=351.95, M S_{\text {error }}=2919.28, p$ $<.001, \eta_{p}^{2}=0.767$. Critically, the interaction of Posture by Congruency, was not significant, $F(2,214)$ $=1.36, M S_{\text {error }}=742.61, p=.258, \eta_{p}{ }^{2}=0.013$. Follow up analyses of Congruency effect revealed no Facilitation effect (Neutral - Congruent trials), $F(1,107)=0.23, M S_{\text {error }}=1109.31, p=.631, \eta_{p}^{2}=.002$. Nor was Facilitation affected by Posture, $F(1,107)=0.73, M S_{\text {error }}=384.27, p=.395, \eta_{p}^{2}=0.007$. There

\footnotetext{
${ }^{1}$ Responses of $205 \mathrm{~ms}$ or less were removed as these were considered response artifacts (e.g., coughing, sneezing, breathing, aberrant vocal response). The 205-ms cut-off value was chosen based on visual inspection of the response time distribution and auditory confirmation.

${ }^{2}$ Rosenbaum et al. (2017) outlier trimming did not consist of the Van Selst \& Jolicoeur (1994) outlier trimming technique.
} 
was an Interference effect (Incongruent - Neutral trials), $F(1,107)=389.86, M S_{\text {error }}=4003.92, p<$ $.001, \eta_{p}^{2}=0.785$., but the Interference effect was not modulated by Posture, $F(1,107)=2.22, M S_{\text {error }}$ $=8.94 .70, p=.139, \eta_{p}^{2}=0.020$.

To recreate as accurately as possible Rosenbaum et al.'s (2017), analyses, the neutral trials were removed from the analyses. There was a significant main effect of Posture, $F(1,107)=19.30, M S_{\text {error }}$ $=3077.00, p<.001, \eta_{p}^{2}=.153$ There was also a significant main effect of Congruency, $F(1,107)=$ 417.36, $M S_{\text {error }}=3644.62, p<.001, \eta_{p}^{2}=.796$. The interaction of Posture by Congruency was not significant $F(1,107)=0.82, M S_{\text {error }}=948.86 p=.369, \eta_{p}^{2}=0.008, \mathbf{B F}=6.31 p_{\mathrm{BIC}}\left(\mathbf{H}_{\mathbf{0}} \mid \mathbf{D}\right)=. \mathbf{1 6}$. The Bayes Factor favoured the null interaction $\mathbf{6 . 3}$ times more than the alternative indicating that the $\mathbf{1 1 6}$ ms Stroop effect in the Standing condition was not reliably smaller than the $121 \mathrm{~ms}$ Stroop effect in the Sitting condition.

PEs. There was no main effect of Posture, $F(1,107)=.02, M S_{\text {error }}=3.72, p=0.894, \eta_{p}^{2}<$ .001. There was a main effect of Congruency, $F(2,214)=37.07, M S_{\text {error }}=7.09, p<.001, \eta_{p}^{2}=0.257$. The Posture by Congruency interaction was not significant, $F(2,214)=0.20, M S_{\text {error }}=3.19, p=0.817$, $\eta_{p}^{2}=.002$. Follow up analyses of Congruency revealed an overall Facilitation effect (Neutral Congruent trials), $F(1,107)=7.09, M S_{\text {error }}=0.45, p=.009, \eta_{p}^{2}=0.062$. There was no Facilitation by Posture interaction, $F(1,107)=0.05, M S_{\text {error }}=0.39, p=.822, \eta_{p}^{2}=0.001$. There was an Interference effect (Incongruent - Neutral trials), $F(1,107)=36.09, M S_{\text {error }}=9.90, p<.001, \eta_{p}{ }^{2}=0.252$. The Interference effect was not modulated by Posture, $F(1,107)=0.23, M S_{\text {error }}=4.74, p=.632, \eta_{p}^{2}=0.002$.

We again recreated Rosenbaum et al.'s (2017), method of analysis by removing the Neutral trials. There was no main effect of Posture, $F(1,107)=0.07, M S_{\text {error }}=4.99, p=0.787, \eta_{p}^{2}=0.001$. There was a main effect of Congruency, $F(1,107)=39.18, M S_{\text {error }}=10.92, p<.001, \eta_{p}^{2}=0.268$. The Posture by Congruency interaction was not significant $F(1,107)=0.19, M S_{\text {error }}=4.43, p=0.668, \eta_{p}^{2}=$ 
.002 , indicating that the $\mathbf{2 . 0 8} \%$ Stroop effect in the Standing condition did not differ from the $\mathbf{1 . 9 0 \%}$ Stroop effect in the Sitting condition.

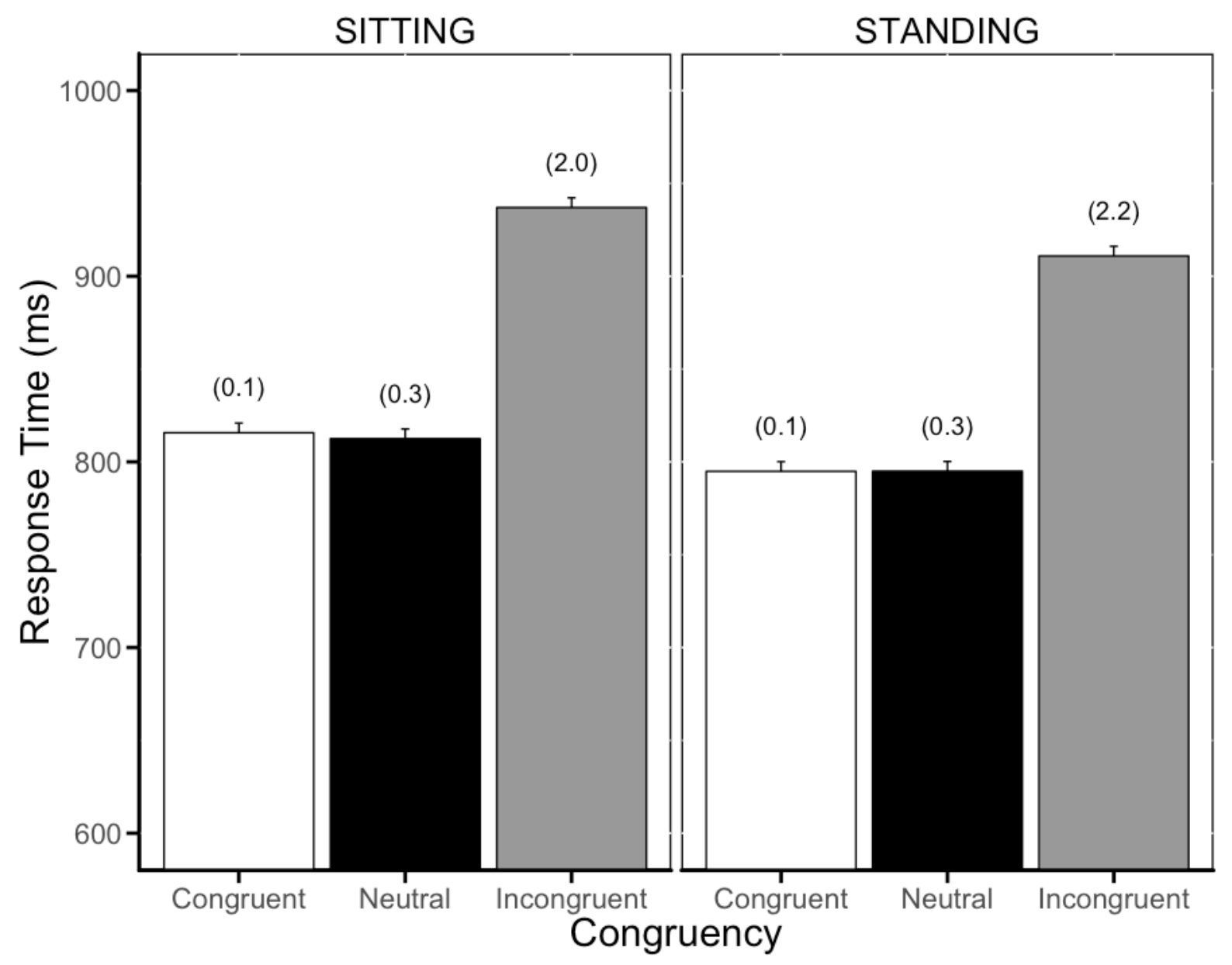

Figure 1. Mean Response Times and mean Percentage Error as a function of Posture and Congruency from Experiment 1. Error bars represent the 95\% confidence intervals calculated according to Loftus and Masson (1994). 


\section{Discussion}

In a large sample of participants $(\mathrm{N}=108)$ we observed the standard Stroop effect, in which responses on incongruent trials were slower than those on both congruent and neutral trials, which did not differ from each other. Further, sitting led to overall slower performance than did standing. Critically, we did not find an influence of posture (Sitting vs. Standing) on either Stroop facilitation or interference. We note that one logical possibility for the failed replication of Rosenbaum et al. (2017) is that the neutral trials that we included in our study and which were not present in Rosenbaum et al.'s design, might have eliminated the impact of posture that was found by Rosenbaum et al. However, while we acknowledge this as a possibility, it is unclear exactly why the inclusion of neutral trials would matter in this way. We should also note one additional potential weakness of our study: We included practice trials only at the beginning of the experiment, which means that participants would only have the opportunity to practice responding in whatever posture they were assigned to first, and not the posture they took up in the latter part of the experiment. 


\section{Experiment 2}

Having failed to find an influence of posture on the magnitude of interference or facilitation in the Stroop task, we conducted another attempted replication of Rosenbaum et al.'s (2017) study, this time without the inclusion of neutral trials so that our design more closely matched theirs. Several additional changes were made to maximize the likelihood of replicating the original study. Specifically, in addition to excluding the neutral trials from Experiment 2 and including explicit postural instructions, Experiment 2 differed from Experiment 1 in that participants had to first complete a series of practice trials prior to beginning the experimental trials in both the sitting and standing conditions and the number of trials in each condition was also increased. These changes are outlined below.

\section{Method}

Participants. As in Experiment 1, 122 University of Waterloo undergraduates participated for course credit.

Stimuli and Apparatus. The apparatus and the Congruent and Incongruent stimuli were identical to those used in Experiment 1.

Procedure. Identical to Experiment 1 with the following exceptions: First, we included 24 practice trials before the initiation of the experimental trials in both the sitting and standing conditions (in Experiment 1 practice trials were only present at the beginning of the study). Second, to remain consistent with Rosenbaum et al. (2017) and Experiment 1 presented here, we maintained equal numbers of Congruent and Incongruent trials. However, we increased the number of trials in each condition to increase the resolution of the performance estimates in each condition. There were 60 trials in both the Congruent, and Incongruent conditions, with fifteen repetitions of each hue in a given condition. Finally, participants in both the Sitting and Standing conditions were instructed to keep their feet flat on the floor approximately hip-width apart and to avoid putting their hands on the 
desk, as well as to avoid leaning on the desk (since leaning on the desk would reduce postural demands in the standing condition; this explicit instruction was not given in Experiment 1).

\section{Results}

As in Experiment 1, the RT and PE data (see Figure 2) were analyzed separately using a repeated measures ANOVA with Posture (Sitting vs. Standing) and Congruency (Congruent vs. Incongruent) as within-subjects factors. Two participants were excluded from the analysis because they failed to identify the correct hue on every incongruent trial. Twelve participants were excluded from the analysis due to high levels of missing data $(>20 \%)$ arising from a failure to record vocal responses. For the remaining 108 participants, $2.86 \%$ of the data were removed due to hardware failures. The RT data were analyzed using only correct responses resulting in the removal of an additional $0.83 \%$ of the data. An additional $0.22 \%$ of the correct RT data were excluded due to premature triggering of the voice key $\left(<=200 \mathrm{~ms}^{3}\right)$. The remaining correct RT data was submitted to a recursive data trimming procedure (as in Experiment 1), which resulted in the removal of $1.41 \%$ of the data.

RTs. There were significant main effects of Posture, $F(1,107)=5.93, M S_{\text {error }}=2553.42, p=$ $.007, \eta_{p}^{2}=0.053$, and Congruency, $F(1,107)=473.35, M S_{\text {error }}=2603.64, p<.001, \eta_{p}^{2}=0.816$. Critically, the interaction of Position by Congruency, was not significant, $F(1,107)=0.33, M S_{\text {error }}=538.57, p=$ $.568, \eta_{p}^{2}=.003, \mathbf{B F}=\mathbf{7 . 9 9}, p_{\mathrm{BIC}}\left(\mathbf{H}_{\mathbf{0}} \mid \mathbf{D}\right)=\mathbf{. 1 3}$. The Bayes Factor favoured the null interaction $\mathbf{8 . 0}$ times more than the alternative indicating that the $\mathbf{1 0 6} \mathrm{ms}$ Stroop effect in the Standing condition did not differ from the $108 \mathrm{~ms}$ Stroop effect in the Sitting condition.

\footnotetext{
${ }^{3}$ Responses of $200 \mathrm{~ms}$ or less were removed as these were considered response artifacts (e.g., coughing, sneezing, breathing, aberrant vocal response). The $200 \mathrm{~ms}$ cut-off value was chosen based on visual inspection of the response time distribution and auditory confirmation. The response time cut-off for this experiment was slightly different than the previous experiment because the discontinuity in the response time distribution occurred at $200 \mathrm{~ms}$ rather $205 \mathrm{~ms}$.
} 
PEs. There was no main effect of Posture, $F(1,107)=0.12, M S_{\text {error }}=1.37, p=.734, \eta_{p}^{2}=.001$. There was a main effect of Congruency, $F(1,107)=55.03, M S_{\text {error }}=4.18, p<.001, \eta_{p}^{2}=0.340$. The Posture by Congruency interaction was not significant $F(1,107)=0.92, M S_{\text {error }}=1.17, p=.340, \eta_{p}^{2}=$ 0.009, indicating that the $\mathbf{1 . 3 6} \%$ Stroop effect in the Standing condition did not differ from the $\mathbf{1 . 5 5 \%}$ Stroop effect in the Sitting condition.

\section{Discussion}

Consistent with Experiment 1, Experiment 2 failed to reveal an influence of Posture (Sitting vs. Standing) on the magnitude of the Stroop effect. Importantly, Experiment 2 again included a relatively large sample $(\mathrm{N}=108)$, one which was substantially larger than the samples $(\mathrm{N}=50$ or less) in the studies reported by Rosenbaum et al. (2017). In addition, relative to Experiment 1, in Experiment 2 our manipulation of posture was more rigorous, and we increased the number of trials in the congruent and incongruent conditions to increase our precision to detect possible differences between conditions. Given our null result across both Experiments 1 and 2, our conclusion is that an influence of posture on the magnitude of the Stroop effect is less reliable than might be inferred from the Rosenbaum et al. findings. 


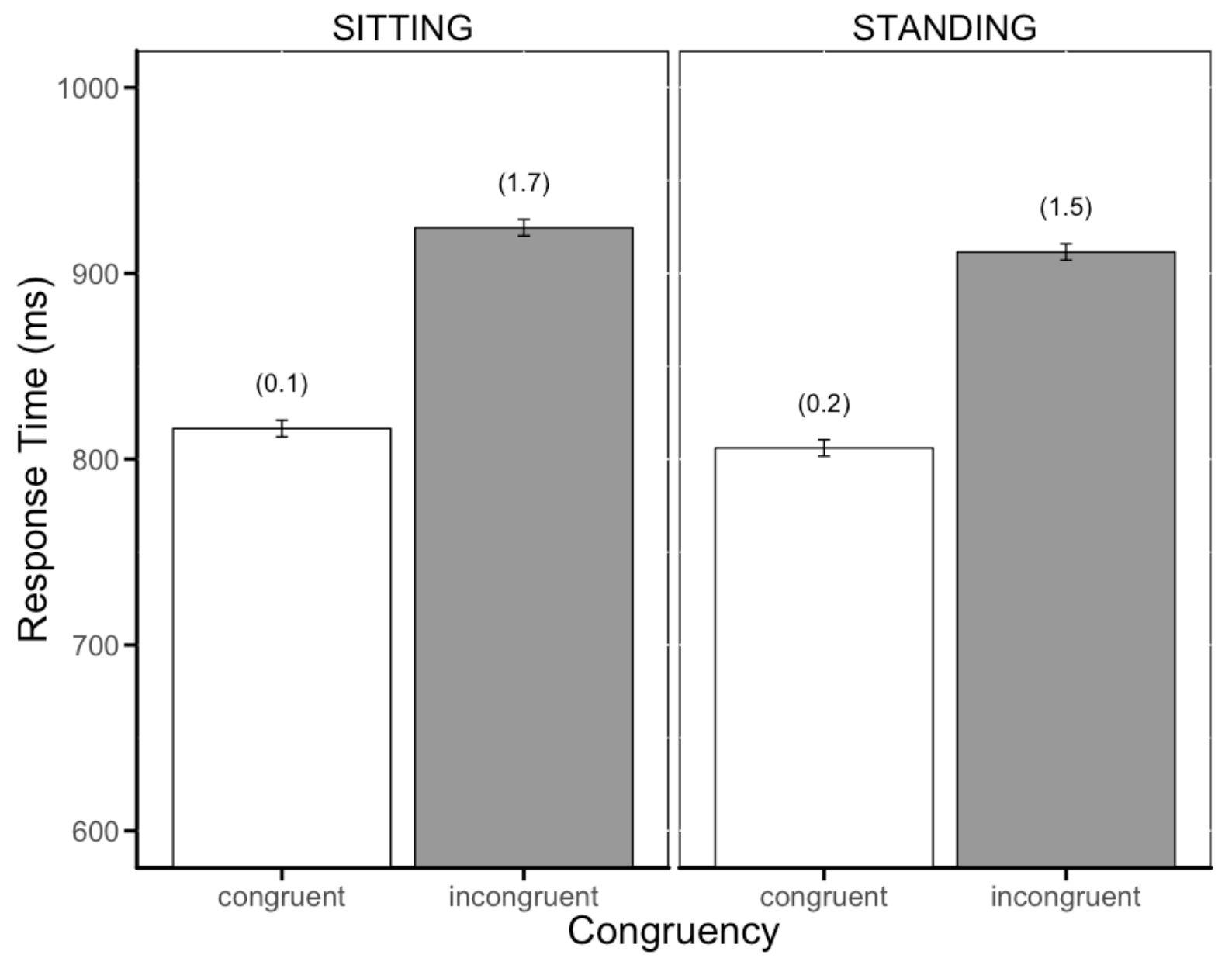

Figure 2. Mean Response Times and mean Percentage Error as a function of Posture and Congruency from Experiment 2. Error bars represent the 95\% confidence intervals are calculated using Loftus and Masson (1994). 


\section{General Discussion}

The work presented here had two primary aims. The first aim was to replicate the intriguing findings reported by Rosenbaum et al. (2017), in which posture (Sitting vs. Standing) modulated the magnitude of the Stroop effect. The second aim was to determine exactly how posture influences performance on the Stroop task by examining whether the influence of posture manifested as an influence on Stroop interference or facilitation or both. Across both studies we consistently found a robust Stroop effect (poorer performance on incongruent trials than on congruent (and neutral) trials) but failed to find any impact of posture on the magnitude of the Stroop effect. Our failure to detect such an impact occurred regardless of the presence of neutral trials in the experiment and regardless of whether participants were provided with explicit instructions to focus on their posture. Based on our findings, we conclude that the results reported by Rosenbaum et al. are less robust than the original report suggests.

\section{Concurrent Replications}

While the studies reported here were being conducted at the University of Waterloo, an independent attempt at a replication of Rosenbaum et al.'s (2017) results was also initiated at Trent University. This replication attempt also included two experiments (referred here as Trent Experiments 1 and 2) ${ }^{4}$. While the two Trent Experiments included only slight modifications of Rosenbaum et al.'s original design, both experiment failed to yield any influence of posture on the magnitude of the Stroop effect. These experiments are described below because they further bolster the present conclusion that Rosenbaum et al.'s findings are difficult to replicate.

In Trent Experiment 1, the specific aim was to evaluate whether the influence of posture on the magnitude of the Stroop effect would manifest even when participants were required to make

\footnotetext{
4 The Trent experiments 1 and 2 were ultimately combined with the current studies in a recent submission to the journal Psychological Science.
} 
manual responses rather than the verbal responses participants made in the studies reported by Rosenbaum et al. (and in the present Experiments 1 and 2). The reasoning was that if posture influenced attentional processes, as Rosenbaum et al. theorized, then posture should influence the magnitude of the Stroop effect independent of the mode of response (vocal or manual). Accordingly, it was hypothesized that relative to sitting, standing should decrease the magnitude of the Stroop effect even when participants are required to respond manually. The results of Trent Experiment 1, based on a relatively large sample size $(\mathrm{N}=98)$, showed the standard Stroop effect, but no reliable influence of posture on the magnitude of the Stroop effect (see Appendix E for a depiction of the results).

In Trent Experiment 2, the manipulation of posture was changed with the aim of increasing the likelihood of detecting an influence of posture on the magnitude of the Stroop effect. Recall that Rosenbaum et al. (2017) posited that the Stroop effect ought to be smaller when standing than when sitting because standing requires that more cognitive resources be devoted to postural muscle control than does sitting. They argued that devoting more resources to postural muscle control leaves fewer resources for processing the distracting Stroop words (because the pool of resources is assumed to be fixed) when standing than while sitting, with the end result being less Stroop interference when standing than when sitting. Based on this theoretical framework, it was reasoned that compared to sitting (or standing on two feet), having people stand on one foot should increase the devotion of cognitive resources to postural muscle control (to maintain balance), and that this would make even fewer resources available to process the Stroop distractors, thus leading to a substantive reduction in the magnitude of the Stroop effect. In line with this reasoning, in Trent Experiment 2 participants completed the Stroop task while sitting and while standing on one foot. Importantly, despite a relatively large sample $(\mathrm{N}=78)$, Trent Experiment 2 failed to produce any evidence to support the notion that posture influences the magnitude of the Stroop effect (see Appendix F for a depiction of 
the results). This failure occurred despite the clever attempt to increase the posture-related differences in cognitive load between the sitting and standing conditions

A much stronger conclusion can be drawn when the present data are analyzed together with the data form the Trent Experiments and the data reported by Rosenbaum et al. (2017; which were included in their Supplementary Materials). The RT data from each of the two experiments reported here, and from the two Trent Experiments, and from the three experiments reported by Rosenbaum et al. were analyzed (see Table 1) using Robust statistical methods as recommended by Wilcox (1998). Here we used a robust mixed model ANOVA with 20\% Windsorized means. Factors included Counterbalance (sitting first vs. standing first), Posture (sitting vs. standing) and Congruency (Congruent vs. Incongruent). These analyses revealed that only one of the five studies included in the analysis showed a significant influence of posture on the magnitude of the Stroop effect. Thus, taken together, the available evidence does not seem to support the claim that posture (sitting vs. standing) influences the magnitude of the Stroop effect. 
Table 1.

Analysis of the four experiments reported in the present paper and the three experiments reported by Rosenbaum et al. (2017) using a robust mixed model ANOVA with 20\% Windsorized means. Factors included Counterbalance (sitting first vs. standing first), Posture (sitting vs. standing) and Congruency (Congruent vs. Incongruent).

\begin{tabular}{|l|l|l|l|l|}
\hline Data from: & $\begin{array}{l}\text { Experiment } \\
(\mathrm{N})\end{array}$ & Effect & $\begin{array}{l}\text { Reported } \\
\text { Effect Size } \\
\eta_{\mathrm{p}}{ }^{2}\end{array}$ & $\begin{array}{l}\text { Outcome of Robust } \\
\text { Analysis }\end{array}$ \\
\hline University of Waterloo & $1(\mathrm{~N}=108)$ & Posture x Congruency & .008 & $\mathrm{~F}=.814, \mathrm{p}=.367$ \\
\hline University of Waterloo & $2(\mathrm{~N}=108)$ & Posture x Congruency & .003 & $\mathrm{~F}=1.35, \mathrm{p}=.245$ \\
\hline Trent University & $1(\mathrm{~N}=99)$ & Posture x Congruency & .001 & $\mathrm{~F}=0.06, \mathrm{p}=.810$ \\
\hline Trent University & $2(\mathrm{~N}=80)$ & Posture x Congruency & .001 & $\mathrm{~F}=.261, \mathrm{p}=.609$ \\
\hline Tel Aviv University & $1(\mathrm{~N}=17)$ & Posture x Congruency & .263 & $\mathrm{~F}=3.653, \mathrm{p}=.056$ \\
\hline Tel Aviv University & $2(\mathrm{~N}=16)$ & Posture x Congruency & .213 & $\mathrm{~F}=1.563, \mathrm{p}=.211$ \\
\hline Ariel University & $3(\mathrm{~N}=50)$ & Posture x Congruency & .155 & $\mathrm{~F}=4.699, \mathrm{p}=.030$ \\
\hline
\end{tabular}




\section{Future Directions}

One of the reasons we were interested in building on Rosenbaum et al.'s findings was that if the originally reported findings held, they would provide compelling support of embodied views of cognition (Barsalou, 2008; Matheson, \& Barsalou, 2018; Wilson, \& Foglia, 2011; Winkielman, Niedenthal Wielgosz, Eelen, \& Kavanagh, 2015; Shapiro, 2010). Unfortunately, as it stands, it seems that this is not the case. However, the embodied view of cognition suggests another interesting possibility for future research. Specifically, because the influence bypothesis is considered to be bidirectional (Matheson \& Barsalou, 2018), future studies might examine the influence of changes in Stroop-related cognitive demands on participants' postural choices. That is, participants might be more likely to choose to sit rather than stand when completing a block of more difficult incongruent Stroop trials than when completing a block of easier congruent Stroop trials.

Additionally, although we did not find any evidence that postural changes influence Stroop performance, there remains the possibility that relative to sitting, standing does indeed consume more attentional resources as Rosenbaum et al. suggest, but that the resources devoted to standing-related postural control are not taken from the primary task, instead they are taken from concurrent taskunrelated mental activity, such as mind wandering. Consistent with this possibility, there is evidence that people do mind wander during the Stroop task (Thomson, Besner \& Smilek, 2013) and that mind wandering consumes attentional resources (see Smallwood \& Schooler, 2006 for a review). In addition, increasing cognitive load typically reduces rates of mind wandering (Geden, Staicu \& Feng, 2018; McVay, Meier, Touron, \& Kane, 2013; Smallwood \& Andrews-Hanna, 2013; Thomson et al., 2013), which is consistent with the possibility that increasing cognitive load by having people stand as opposed to sit, may borrow resources from mind wandering, thus reducing levels of mind wandering without influencing task performance. Therefore, another possible future direction is to examine the influence of posture on individuals' levels of mind wandering. A simple modification of the design 
presented in this paper could involve including mind wandering thought probes during the Stroop task in both sitting and standing conditions.

Future research might also further explore the main effect of posture (sitting vs. standing) that was found across the experiments presented here. With regard to this main effect, it is important to note that this main effect was not found in the Trent Experiments 1 and 2. As a result, at this point it is unclear how robust this main effect is and what factors might influence the magnitude of this main effect, should it be robust at least under some circumstances. One key difference between the present studies and the Trent studies involves the response mode; specifically, the present studies used a vocal response and the Trent studies using a button press response. Accordingly, it could be that standing allows people to produce faster vocal responses, but not manual responses, perhaps because the vocal responses are more automatic. Future studies might focus on a direct comparison of how posture influences response time of vocal and manual responses.

\section{Replication}

The present findings add to the growing concern regarding the replicability of key findings in psychological science (Colling \& Szűc, 2018; Maizey \& Tzavella, 2019; Schooler, 2014; Trafimow, 2018;). Indeed, the present findings can be seen as an instance of the broader trend that has been referred to by some as a "replication crisis" (Colling \& Szűc, 2018; Maizey \& Tzavella, 2019; Schooler Schooler, 2014; Trafimow, 2018) in psychological science. Going forward, it is important to keep in mind that "reproducibility is the hallmark of credible scientific evidence" (Open Science Collaboration, 2015, p.4716-4717). Only through multiple rigorous replications of key phenomena of interest can we be confident that the phenomena capture more than just chance outcomes.

Yet there are still some, perhaps, who feel that replication in and of itself does not provide a sufficiently valuable contribution to the scientific community. Earp and Trafimow (2015) bring this to light when they state: 
"Part of the problem [with conducting replications] is the lack of prestige associated with carrying out replications (Smith,1970). To put simply, few would want to be seen by their peers as merely "copying” another's work (e.g., Mulkay and Gilbert, 1986); and few could afford to be seen in this way by tenure committees or by the funding bodies that sponsor their research. Thus, while "a field that replicates its work is [seen as] rigorous and scientifically sound" - according to Makel et al. (2012) - psychologist who actually conduct those replications "are looked down on as bricklayers and not [as] advancing [scientific] knowledge" (p.537). In consequence, actual replication attempts are rare.”

At the risk of being labeled 'brick layers,' we have opted to contribute to making our field "rigorous and scientifically sound".

\section{Concluding Comments}

In conclusion, and on a positive note, our findings are consistent with the general trend in the broader literature, which is that posture does not substantially influence cognitive performance (Bantoft et al., 2016; Patston et al., 2017; Russell et al., 2016). We note that there is a 'bright side' to our failure to replicate Rosenbaum et al.'s (2017) findings. The originally reported effect, showing a reduction in the magnitude of the Stroop effect, implied that standing consumes cognitive resources, thus leaving fewer resources for the task at hand. Thus, if the original findings held, an effect of posture on the Stroop effect would imply that perhaps relative to sitting, standing could generally impair task performance (e.g., slow reading rate). The finding that postural differences between sitting and standing do not influence the magnitude of the Stroop effect implies that the use of sit-stand stations is likely not going to have a negative impact on cognitive performance (see Bantoft et al. 2016). 


\section{References}

Ashcraft, M. H. (1994). Human memory and cognition. Harper Collins.

Bantoft, C., Summers, M. J., Tranent, P. J., Palmer, M. A., Cooley, P. D., \& Pedersen, S. J. (2016). Effect of standing or walking at a workstation on cognitive function: a randomized counterbalanced trial. Human factors, 58(1), 140-149.

Barsalou, L. W. (2008). Grounded cognition. Annual. Review of Psychology., 59, 617-645.

Bernardi, N. F., Schories, A., Jabusch, H. C., Colombo, B., \& Altenmueller, E. (2013). Mental practice in music memorization: an ecological-empirical study. Music Perception: An Interdisciplinary Journal, 30(3), 275-290.

Besner, D., \& Reynolds, M. (2017). Is semantic activation from print capacity limited? Evidence from the psychological refractory period paradigm. Psychonomic bulletin \& review, 24(3), 907913.

Besner, D., Risko, E. F., Stolz, J. A., White, D., Reynolds, M., O’Malley, S., \& Robidoux, S. (2016). Varieties of attention: Their roles in visual word identification. Current Directions in Psychological Science, 25(3), 162-168.

Burhans, R. S., Richman, C. L., \& Bergey, D. B. (1988). Mental imagery training: Effects on running speed performance. International Journal of Sport Psychology 
Canadian Centre for Occupational Health and Safety (2019). Office ergonomics: Sit/stand desks. Retrieved from https://www.ccohs.ca/oshanswers/ergonomics/office/sit_stand_desk.html

Caron, E. E., Reynolds, M.G., Ralph, B.C.W., Carriere, J.S.A., Besner, D., Smilek, D. (2019). Does posture influence the Stroop effect? Manuscript submitted for publication.

Colling, L. J., \& Szűcs, D. (2018). Statistical inference and the replication crisis. Review of Philosophy and Psychology. Advance online publication.

Cooper, A. D., Sterling, C. P., Bacon, M. P., \& Bridgeman, B. (2012). Does action affect perception or memory?. Vision Research, 62, 235-240.

Chau, J. Y., Sukala, W., Fedel, K., Do, A., Engelen, L., Kingham, M., Sainsbury, A., \& Bauman, A. E. (2016). More standing and just as productive: Effects of a sit-stand desk intervention on call center workers' sitting, standing, and productivity at work in the Opt to Stand pilot study. Preventive medicine reports, 3, 68-74.

Danziger, S., Levav, J., \& Avnaim-Pesso, L. (2011). Extraneous factors in judicial decisions. Proceedings of the National Academy of Sciences, 108(17), 6889-6892.

Earp, B. D., \& Trafimow, D. (2015). Replication, falsification, and the crisis of confidence in social psychology. Frontiers in psychology, 6, 621. 
Ebara, T., Kubo, T., Inoue, T., Murasaki, G. I., Takeyama, H., Sato, T., Suzumura, H., Niwa, S., Takanishi, T., Tachi, N., \& Itani, T. (2008). Effects of adjustable sit-stand VDT workstations on workers' musculoskeletal discomfort, alertness and performance. Industrial health, 46(5), 497-505.

Ekelund, U., Steene-Johannessen, J., Brown, W. J., Fagerland, M. W., Owen, N., Powell, K. E., Bauman, A., Min Lee, I., Lancet Physical Activity Series 2 Executive Committee, \& Lancet Sedentary Behaviour Working Group. (2016). Does physical activity attenuate, or even eliminate, the detrimental association of sitting time with mortality? A harmonised metaanalysis of data from more than 1 million men and women. The Lancet, 388(10051), 13021310.

Garrett, G., Benden, M., Mehta, R., Pickens, A., Peres, S. C., \& Zhao, H. (2016). Call center productivity over 6 months following a standing desk intervention. IIE Transactions on Occupational Ergonomics and Human Factors, 4, 188-195.

Geden, M., Staicu, A. M., \& Feng, J. (2018). The impacts of perceptual load and driving duration on mind wandering in driving. Transportation research part F: traffic psychology and behaviour, 57, 7583.

Kuhn, M. R., Schwanenflugel, P. J., Meisinger, E. B., Levy, B. A., \& Rasinski, T. V. (2010). Aligning theory and assessment of reading fluency: Automaticity, prosody, and definitions of fluency. Reading research quarterly, 45(2), 230-251. 
Labuschagne, E. M., \& Besner, D. (2015). Automaticity revisited: when print doesn't activate semantics. Frontiers in Psychology, 6, 117.

Loftus, G. R., \& Masson, M. E. (1994). Using confidence intervals in within-subject designs. Psychonomic bulletin \& review, 1(4), 476-490.

Logan, G. D. (1997). Automaticity and reading: Perspectives from the instance theory of automatization. Reading \& Writing Quarterly: Overcoming Learning Difficulties, 13(2), 123-146.

Louridas, M., Bonrath, E. M., Sinclair, D. A., Dedy, N. J., \& Grantcharov, T. P. (2015). Randomized clinical trial to evaluate mental practice in enhancing advanced laparoscopic surgical performance. British Journal of Surgery, 102(1), 37-44.

MacEwen, B. T., MacDonald, D. J., \& Burr, J. F. (2015). A systematic review of standing and treadmill desks in the workplace. Preventive medicine, 70, 50-58.

Maizey, L., \& Tzavella, L. (2019). Barriers and solutions for early career researchers in tackling the reproducibility crisis in cognitive neuroscience. Cortex: A Journal Devoted to the Study of the Nervous System and Behavior, 113, 357-359.

Makel, M. C., Plucker, J. A., and Hegarty, B. (2012). Replications in psychology research how often do they really occur? Perspect. Psychol. Sci. 7, 537-542. doi: 10.1177/1745691612460688 
Matheson, H. E., \& Barsalou, L. W. (2018). Embodiment and grounding in cognitive neuroscience. Stevens' Handbook of Experimental Psychology and Cognitive Neuroscience, 3, 1-27.

McVay, J. C., Meier, M. E., Touron, D. R., \& Kane, M. J. (2013). Aging ebbs the flow of thought: Adult age differences in mind wandering, executive control, and self-evaluation. Acta psychologica, 142(1), 136-147.

Mulkay, M., \& Gilbert, G. N. (1986). Replication and mere replication. Philosophy of the Social Sciences, 16(1), 21-37.

Oberman, L. M., Winkielman, P., \& Ramachandran, V. S. (2007). Face to face: Blocking facial mimicry can selectively impair recognition of emotional expressions. Social neuroscience, 2(3-4), 167-178.

Open Science Collaboration (2015). Estimating the reproducibility of psychological science. Science, 349, 47161-47168. https://doi.org/10.1126/science.aac4716

Patston, L., Henry, A. N., McEwen, M., Mannion, J., \& Ewens-Volynkina, L. A. (2017). Thinking while standing: An exploratory study on the effect of standing on cognitive performance. Unitec ePress Occasional and Discussion Paper Series (2017:3). Retrieved from http://www.unitec.ac.nz/epress 
Proper, K. I., Singh, A. S., Van Mechelen, W., \& Chinapaw, M. J. (2011). Sedentary behaviors and health outcomes among adults: a systematic review of prospective studies. American journal of preventive medicine, 40(2), 174-182.

Rayner, K., \& Pollatsek, A. (1989). The psychology of Reading. Englewood Cliffs, NJ: Prentice Hall.

Rosenbaum, D., Mama, Y., \& Algom, D. (2017). Stand by Your Stroop: Standing Up Enhances Selective Attention and Cognitive Control. Psychological Science, 28(12), 1864-1867.

Russell, B. A., Summers, M. J., Tranent, P. J., Palmer, M. A., Cooley, P. D., \& Pedersen, S. J. (2016). A randomised control trial of the cognitive effects of working in a seated as opposed to a standing position in office workers. Ergonomics, 59(6), 737-744.

Schooler, J. W. (2014). Metascience could rescue the 'replication crisis'. Nature News, 515(7525), 9.

Schraefel, M.C., Jay, K., \& Andersen, L. L. (2012). Assessing the effect of self-positioning on cognitive executive function. Journal of Ergonomics, 2(110).

Shapiro, L. (2010). Embodied cognition. Routledge.

Smallwood, J., \& Andrews-Hanna, J. (2013). Not all minds that wander are lost: the importance of a balanced perspective on the mind-wandering state. Frontiers in psychology, 4, 441.

Smallwood, J., \& Schooler, J. W. (2006). The restless mind. Psychological bulletin, 132(6), 946. 
Smith, N. C. (1970). Replication studies: a neglected aspect of psychological research. Am. Psychol. 25, 970-975. doi: 10.1037/h0029774

Stroop, J. R. (1935). Studies of interference in serial verbal reactions. Journal of Experimental Psychology, 18(6), 643.

Thomson, D. R., Besner, D., \& Smilek, D. (2013). In pursuit of off-task thought: mind wanderingperformance trade-offs while reading aloud and color naming. Frontiers in Psychology, 4, 360.

Torbeyns, T., Bailey, S., Bos, I., \& Meeusen, R. (2014). Active workstations to fight sedentary behaviour. Sports medicine, 44(9), 1261-1273.

Trafimow, D. (2018). An a priori solution to the replication crisis. Philosophical Psychology. Advance online publication.

van der Ploeg, H. P., Chey, T., Korda, R. J., Banks, E., \& Bauman, A. (2012). Sitting time and allcause mortality risk in 222497 Australian adults. Archives of internal medicine, 172(6), 494-500.

Van Selst, M., \& Jolicoeur, P. (1994). A solution to the effect of sample size on outlier elimination. The Quarterly Journal of Experimental Psychology, Section A, 47(3), 631-650.

van Uffelen, J. G., Wong, J., Chau, J. Y., van der Ploeg, H. P., Riphagen, I., Gilson, N. D., Burton, N. W., Healy, G. N., Thorp, A. A., Clark, B. K., Gardiner, P. A., Dunstan, D. W., Bauman, 
A., Owen, N., \& Brown, W. J. (2010). Occupational sitting and health risks: a systematic review. American journal of preventive medicine, 39(4), 379-388.

Voss, M. W., Carr, L. J., Clark, R., \& Weng, T. (2014). Revenge of the "sit” II: Does lifestyle impact neuronal and cognitive health through distinct mechanisms associated with sedentary behavior and physical activity?. Mental Health and Physical Activity, 7(1), 9-24.

White, D., \& Besner, D. (2018). Attentional constraints on semantic activation: Evidence from Stroop's paradigm. Acta psychologica, 189, 4-11.

Wilcox, R. R. (1998). The goals and strategies of robust methods. British Journal of Mathematical and Statistical Psychology, 51(1), 1-39.

Wilson, R. A., \& Foglia, L. (2011). Embodied cognition. The Stanford Encyclopedia of Philosophy (Spring 2017 Edition). Retrieved from https://plato.stanford.edu/archives/spr2017/entries/ embodied-cognition/

Winkielman, P., Niedenthal, P., Wielgosz, J., Eelen, J., \& Kavanagh, L. C. (2015). Embodiment of cognition and emotion. APA handbook of personality and social psychology, 1, 151-175.

Witt, J. K. (2011). Action's effect on perception. Current Directions in Psychological Science, 20(3), 201 206. 
Witt, J.K., Proffitt, D.R., \& Epstein, W. (2004). Perceiving distance: A role of effort and intent. Perception, 33, 570-590.

Witt, J.K., Proffitt, D.R., \& Epstein, W. (2005). Tool use affects perceived distance but only when you intend to use it. Journal of Experimental Psychology: Human Perception and Performance, 31, 880-888. 


\section{Appendix A}

\section{Experiment 1}

Mean response times and percentage error from Experiment 1 as a function of Posture (Sitting vs. Standing), Congruency (Incongruent, Neutral, Congruent) and Block Number (1 vs. 2). 95\% confidence intervals were calculated using the error term from the highest order interaction as suggested by Loftus and Masson (1994).

\begin{tabular}{|c|c|c|c|c|c|c|c|c|c|}
\hline \multirow[b]{4}{*}{ Posture } & \multirow[b]{4}{*}{ Congruency } & \multicolumn{6}{|c|}{ esponse Time } & \multicolumn{2}{|c|}{ Percent Error } \\
\hline & & \multicolumn{3}{|c|}{ Block 1} & \multicolumn{3}{|l|}{ Block 2} & \multirow[t]{3}{*}{ Block 1} & \multirow[t]{3}{*}{ Block 2} \\
\hline & & \multicolumn{3}{|c|}{$95 \% \mathrm{Cl}$} & \multicolumn{3}{|c|}{$95 \% \mathrm{Cl}$} & & \\
\hline & & Mean & Min & Max & Mean & Min & Max & & \\
\hline \multirow[t]{6}{*}{ Sitting } & Incongruent & 939 & 93 & 9 & 935 & 930 & 90 & 1.80 & 2.20 \\
\hline & Neutral & 811 & 806 & 816 & 81 & 809 & 819 & 0.30 & 0.0 \\
\hline & Congruent & 808 & 803 & 813 & 823 & 818 & 828 & 0.20 & 0.10 \\
\hline & $\begin{array}{l}\text { Stroop Effect } \\
\text { Facilitation }\end{array}$ & 131 & & & 112 & & & 1.6 & 2.1 \\
\hline & $\begin{array}{l}\text { Effect } \\
\text { Interference }\end{array}$ & 3 & & & -9 & & & 0.1 & 0.3 \\
\hline & Effect & 128 & & & 122 & & & 1.5 & 1.8 \\
\hline \multirow[t]{6}{*}{ Standing } & Incongruent & 92 & 919 & 929 & 898 & 893 & 903 & 2.20 & 2.10 \\
\hline & Neutral & 793 & 788 & 798 & 797 & 792 & 802 & 0.20 & 0.0 \\
\hline & Congruent & 796 & 791 & 801 & 79 & 789 & 799 & 0.10 & 0.20 \\
\hline & $\begin{array}{l}\text { Stroop effect } \\
\text { Facilitation }\end{array}$ & 129 & & & 103 & & & 2.10 & 1.90 \\
\hline & $\begin{array}{l}\text { effect } \\
\text { Interference }\end{array}$ & -3 & & & 3 & & & 0.10 & 0.20 \\
\hline & effect & 132 & & & 100 & & & 2.00 & 1.70 \\
\hline
\end{tabular}




\section{Appendix B}

\section{Experiment 1}

\section{Additional analyses examining the full design including Posture (Sitting vs. Standing), Congruency (Incongruent, Neutral, Congruent) and Counterbalance (Sitting first vs. Standing first) a within-subject factors within the ANOVA.}

$R$ statistical software (version 3.3) was used to analyze the data. ANOVAs were run using the ez package (version .0). Bayes factors were calculated using the BayesFactor package (version $0.9 .1-.2)$.

Prior to analyzing the RT and PE data, 1 participant was excluded from the analysis due to high levels of missing data $(>20 \%)$ arising from a failure to record vocal responses. For the remaining 108 participants, $2.09 \%$ of the data was removed due to hardware failures. The RT data were analyzed using only correct responses resulting in the removal of an additional $0.81 \%$ of the data. An additional $0.2 \%$ of the correct RT data were excluded due to premature triggering of the voice key ( $<=205 \mathrm{~ms}$ ). The remaining correct RT data was submitted to a recursive data trimming procedure in which the criterion for outlier removal is calculated separately for each participant in each cell based on sample size (Van Selst \& Jolicoeur, 199). This resulted in the removal of 1.26\% of the data. 


\section{Data Analysis: Experiment 1}

\section{Analysis 1: Full Design}

\section{Design}

Counterbalance (Sitting first vs. Standing first) $\mathrm{x}$

Posture (Sitting vs. Standing) $\mathrm{x}$

Congruency (Incongruent, Neutral, Congruent)

\section{Experiment 1: Full Design: Response Time Analysis}

$($ Intercept $): F(1,106)=51.73, \mathrm{MSE}=85317.2, \mathrm{p}<0.001, \eta_{\mathrm{p}}{ }^{2}=0.981$

Counterbalance: $\mathrm{F}(1,106)=0.07, \mathrm{MSE}=85317.2, \mathrm{p}=0.787, \eta_{\mathrm{p}}{ }^{2}=0.001$

Congruency: $F(2,212)=351.19, \operatorname{MSE}=2925.60, \mathrm{p}<0.001, \eta_{\mathrm{p}}{ }^{2}=0.768$

Posture: $\mathrm{F}(1,106)=18.78, \mathrm{MSE}=3980.9, \mathrm{p}<0.001, \eta_{\mathrm{p}}{ }^{2}=0.151$

Counterbalance:Congruency: $\mathrm{F}(2,212)=0.77, \mathrm{MSE}=2925.60, \mathrm{p}=0.65, \eta_{\mathrm{p}}{ }^{2}=0.007$

Counterbalance:Posture: $\mathrm{F}(1,106)=0.10, \mathrm{MSE}=3980.9, \mathrm{p}=0.77, \eta_{\mathrm{p}}{ }^{2}=0.001$

Congruency:Posture: $\mathrm{F}(2,212)=1.9, \mathrm{MSE}=679.1, \mathrm{p}=0.228, \eta_{\mathrm{p}}{ }^{2}=0.01$

Counterbalance:Congruency:Posture: $\mathrm{F}(2,212)=10.95, \mathrm{MSE}=679.1,<0.001, \eta_{\mathrm{p}}{ }^{2}=$ 0.09 


\section{Experiment 1: Full Design: Percentage Error Analysis}

$\left(\right.$ Intercept): $\mathrm{F}(1,106)=3.525, \mathrm{MSE}=10.95, \mathrm{p}<0.001, \eta_{\mathrm{p}}{ }^{2}=0.291$

Counterbalance: $\mathrm{F}(1,106)=0.008, \mathrm{MSE}=10.95, \mathrm{p}=0.929, \eta_{\mathrm{p}}^{2}<0.001$

Posture: $\mathrm{F}(1,106)=0.018, \mathrm{MSE}=3.7, \mathrm{p}=0.895, \eta_{\mathrm{p}}{ }^{2}<0.001$

Congruency: $\mathrm{F}(2,212)=36.825, \mathrm{MSE}=7.137, \mathrm{p}<0.001, \eta_{\mathrm{p}}{ }^{2}=0.258$

Counterbalance:Posture: $F(1,106)=0.329, \mathrm{MSE}=3.7, \mathrm{p}=0.567, \eta_{\mathrm{p}}{ }^{2}=0.003$

Counterbalance:Congruency: $\mathrm{F}(2,212)=0.306, \mathrm{MSE}=7.137, \mathrm{p}=0.737, \eta_{\mathrm{p}}{ }^{2}=0.003$

Posture:Congruency: $\mathrm{F}(2,212)=0.201, \mathrm{MSE}=3.213, \mathrm{p}=0.818, \eta_{\mathrm{p}}{ }^{2}=0.002$

Counterbalance:Posture:Congruency: $\mathrm{F}(2,212)=0.17, \mathrm{MSE}=3.213, \mathrm{p}=0.8, \eta_{\mathrm{p}}{ }^{2}=$ 0.002 


\section{Analysis 2 (Experiment 1): Without the Neutral Trials}

\section{Design}

Counterbalance (Sitting first vs. Standing first) $\mathrm{x}$

Posture (Sitting vs. Standing) $\mathrm{x}$

Congruency (Incongruent, Congruent)

\section{Experiment 1: Stroop Effect: Response Time Analysis}

$($ Intercept $): F(1,106)=5137.82, \mathrm{MSE}=62859.978, \mathrm{p}<0.001, \eta_{\mathrm{p}}{ }^{2}=0.980$

Counterbalance: $\mathrm{F}(1,106)=0.17, \mathrm{MSE}=62859.978, \mathrm{p}=0.686, \eta_{\mathrm{p}}{ }^{2}=0.002$

Congruency: $\mathrm{F}(1,106)=13.80, \mathrm{MSE}=3675.967, \mathrm{p}<0.001, \eta_{\mathrm{p}}^{2}=0.796$

Posture: $\mathrm{F}(1,106)=19.23, \mathrm{MSE}=3088.009, \mathrm{p}<0.001, \eta_{\mathrm{p}}{ }^{2}=0.15$

Counterbalance:Congruency: $\mathrm{F}(1,106)=0.09, \mathrm{MSE}=3675.967, \mathrm{p}=0.768$, $\eta_{\mathrm{p}}^{2}=0.001$

Counterbalance:Posture: $\mathrm{F}(1,106)=0.62, \mathrm{MSE}=3088.009, \mathrm{p}=0.33, \eta_{\mathrm{p}}{ }^{2}=0.006$

Congruency:Posture: $\mathrm{F}(1,106)=0.92, \mathrm{MSE}=838.127, \mathrm{p}=0.339, \eta_{\mathrm{p}}{ }^{2}=0.009$

Counterbalance:Congruency:Posture: $\mathrm{F}(1,106)=15.1, \mathrm{MSE}=838.127, \mathrm{p}<0.001$, $\eta_{\mathrm{p}}^{2}=0.125$ 


\section{Experiment 1: Stroop Effect: Percentage Error Analysis}

$\left(\right.$ Intercept): $\mathrm{F}(1,106)=1.879, \mathrm{MSE}=12.80, \mathrm{p}<0.001, \eta_{\mathrm{p}}{ }^{2}=0.283$

Counterbalance: $\mathrm{F}(1,106)=0.03, \mathrm{MSE}=12.80, \mathrm{p}=0.86, \eta_{\mathrm{p}}{ }^{2}<0.001$

Posture: $\mathrm{F}(1,106)=0.073, \mathrm{MSE}=5.031, \mathrm{p}=0.788, \eta_{\mathrm{p}}^{2}<0.001$

Congruency: $\mathrm{F}(1,106)=38.98, \mathrm{MSE}=10.989, \mathrm{p}<0.001, \eta_{\mathrm{p}}{ }^{2}<0.269$

Counterbalance:Posture: $\mathrm{F}(1,106)=0.066, \mathrm{MSE}=5.031, \mathrm{p}=0.798, \eta_{\mathrm{p}}{ }^{2}<0.001$

Counterbalance:Congruency: $\mathrm{F}(1,106)=0.358, \mathrm{MSE}=10.989, \mathrm{p}=0.551, \eta_{\mathrm{p}}{ }^{2}=0.003$

Posture:Congruency: $\mathrm{F}(1,106)=0.183, \mathrm{MSE}=.61, \mathrm{p}=0.669, \eta_{\mathrm{p}}^{2}=0.002$

Counterbalance:Posture:Congruency: $\mathrm{F}(1,106)=0.171, \mathrm{MSE}=.61, \mathrm{p}=0.680, \eta_{\mathrm{p}}{ }^{2}=$ 0.002 
Analysis 3 (Experiment 1): Robust Analysis of Experiment 1 Response Time Data (Neutral Trials Removed)

Design

Counterbalance (Sitting first vs. Standing first) $\mathrm{x}$

Posture (Sitting vs. Standing) $\mathrm{x}$

Congruency (Incongruent, Congruent)

\section{Analysis}

The data were analyzed using a robust mixed model ANOVA with 20\% Windsorized means. The functions were programmed by Rand Wilcox (https://dornsife.usc.edu/labs/rwilcox/software/). Version 25 of the source package was used.

Counterbalance: $\mathrm{F}=0.00, \mathrm{p}=0.82$

Posture: $\mathrm{F}=26.29, \mathrm{p}<0.001$

Congruency: $\mathrm{F}=19.733, \mathrm{p}<0.001$

Counterbalance:Posture: $\mathrm{F}=.16, \mathrm{p}=0.02$

Counterbalance: Congruency: $\mathrm{F}=0.311, \mathrm{p}=0.578$

Posture: Congruency: $F=0.665, p=0.15$

Counterbalance:Posture:Congruency: $F=3.865, \mathrm{p}=0.050$ 


\section{Appendix C}

\section{Experiment 2}

Mean response times and percentage error from Experiment 2 as a function of Posture (Sitting vs. Standing), Congruency (Incongruent, Congruent) and Block Number (1 vs. 2). 95\% confidence intervals were calculated using the error term from the highest order interaction as suggested by Loftus and Masson (199).

\begin{tabular}{|c|c|c|c|c|c|c|c|c|c|}
\hline \multirow[b]{4}{*}{ Posture } & \multirow[b]{4}{*}{ Congruency } & \multicolumn{6}{|c|}{ Response Time } & \multicolumn{2}{|c|}{ Percent Error } \\
\hline & & \multicolumn{3}{|l|}{ Block 1} & \multicolumn{3}{|l|}{ Block 2} & \multirow[t]{3}{*}{ Block 1} & \multirow[t]{3}{*}{ Block 2} \\
\hline & & \multirow[b]{2}{*}{ Mean } & \multicolumn{2}{|c|}{$95 \% \mathrm{Cl}$} & \multirow[b]{2}{*}{ Mean } & \multicolumn{2}{|c|}{$95 \% \mathrm{Cl}$} & & \\
\hline & & & Min & Max & & Min & Max & & \\
\hline \multirow[t]{3}{*}{ Sitting } & Incongruent & 922 & 918 & 926 & 927 & 923 & 932 & 1.8 & 1.5 \\
\hline & Congruent & 81 & 809 & 818 & 819 & 815 & 82 & 0.2 & 0 \\
\hline & Stroop Effect & 108 & & & 108 & & & 1.6 & 1.5 \\
\hline \multirow[t]{3}{*}{ Standing } & Incongruent & 925 & 921 & 929 & 898 & 89 & 902 & 1.5 & 1.5 \\
\hline & Congruent & 808 & 803 & 812 & 80 & 800 & 809 & 0.0 & 0.3 \\
\hline & Stroop Effect & 117 & & & 9 & & & 1.5 & 1.2 \\
\hline
\end{tabular}




\section{Appendix D}

Experiment 2

\section{Additional analyses examining the full design including Posture (Sitting vs. Standing), Congruency (Incongruent, Neutral, Congruent) and Counterbalance (Sitting first vs. Standing first) a within-subject factors within the ANOVA.}

Data Analysis: Experiment 2

Analysis 1: Full Design

Design

Counterbalance (Sitting first vs. Standing first) $\mathrm{x}$

Posture (Sitting vs. Standing) $\mathrm{x}$

Congruency (Incongruent, Congruent)

Experiment 2: Response Time Analysis

(Intercept): $\mathrm{F}(1,106)=6325.92, \mathrm{MSE}=51056.15, \mathrm{p}<0.001, \eta_{\mathrm{p}}{ }^{2}=0.98$

Counterbalance: $\mathrm{F}(1,106)=0.22, \mathrm{MSE}=51056.15, \mathrm{p}=0.639, \eta_{\mathrm{p}}{ }^{2}=0.002$

Congruency: $\mathrm{F}(1,106)=75.09, \mathrm{MSE}=259.08, \mathrm{p}<0.001, \eta_{\mathrm{p}}{ }^{2}=0.818$

Posture: $\mathrm{F}(1,106)=5.93, \mathrm{MSE}=255.18, \mathrm{p}=0.017, \eta_{\mathrm{p}}{ }^{2}=0.053$

Counterbalance:Congruency: $\mathrm{F}(1,106)=1.39, \mathrm{MSE}=259.08, \mathrm{p}=0.2, \eta_{\mathrm{p}}{ }^{2}=0.013$

Counterbalance:Posture: $\mathrm{F}(1,106)=0.97, \mathrm{MSE}=255.18, \mathrm{p}=0.327, \eta_{\mathrm{p}}{ }^{2}=0.009$

Congruency:Posture: $\mathrm{F}(1,106)=0.35, \mathrm{MSE}=507.20, \mathrm{p}=0.557, \eta_{\mathrm{p}}{ }^{2}=0.003$

Counterbalance:Congruency:Posture: $\mathrm{F}(1,106)=7.62, \mathrm{MSE}=507.20, \mathrm{p}=0.007$, $\eta_{\mathrm{p}}^{2}=0.067$ 


\section{Experiment 2: Percentage Error Analysis}

(Intercept): $\mathrm{F}(1,106)=70.6, \mathrm{MSE}=.8, \mathrm{p}<0.001, \eta_{\mathrm{p}}{ }^{2}=0.399$

Counterbalance: $\mathrm{F}(1,106)=0.8, \mathrm{MSE}=.82, \mathrm{p}=0.360, \eta_{\mathrm{p}}{ }^{2}=0.008$

Posture: $\mathrm{F}(1,106)=0.12, \mathrm{MSE}=1.38, \mathrm{p}=0.73, \eta_{\mathrm{p}}{ }^{2}=0.001$

Congruency: $\mathrm{F}(1,106)=5.53, \mathrm{MSE}=.22, \mathrm{p}<0.001, \eta_{\mathrm{p}}{ }^{2}=0.30$

Counterbalance:Posture: $\mathrm{F}(1,106)=0.63, \mathrm{MSE}=1.38, \mathrm{p}=0.28, \eta_{\mathrm{p}}{ }^{2}=0.006$

Counterbalance:Congruency: $\mathrm{F}(1,106)=0.03, \mathrm{MSE}=.22, \mathrm{p}=0.869, \eta_{\mathrm{p}}{ }^{2}<0.001$

Posture:Congruency: $\mathrm{F}(1,106)=0.92, \mathrm{MSE}=1.17, \mathrm{p}=0.339, \eta_{\mathrm{p}}{ }^{2}=0.009$

Counterbalance:Posture:Congruency: $\mathrm{F}(1,106)=1.3, \mathrm{MSE}=1.17, \mathrm{p}=0.250, \eta_{\mathrm{p}}{ }^{2}=$ 0.013 


\section{Analysis 2: Robust Analysis of Experiment 2 Response Time Data}

\section{Design}

Counterbalance (Sitting first vs. Standing first) $\mathrm{x}$

Posture (Sitting vs. Standing) $\mathrm{x}$

Congruency (Incongruent, Congruent)

\section{Analysis}

The data were analyzed using a robust mixed model ANOVA with 20\% Windsorized means. The functions were programmed by Rand Wilcox (https://dornsife.usc.edu/labs/rwilcox/software/). Version 25 of the source package was used.

Counterbalance: $\mathrm{F}=0.330, \mathrm{p}=0.566$

Posture: $\mathrm{F}=3.566$, p.value $=0.059$

Congruency: $\mathrm{F}=336.133, \mathrm{p}<0.001$

Counterbalance:Posture: $\mathrm{F}=0.65, \mathrm{p}=0.19$

Counterbalance: Congruency: $\mathrm{F}=1.25, \mathrm{p}=0.263$

Posture: Congruency: $\mathrm{F}=0.870, \mathrm{p}=0.351$

Counterbalance:Posture:Congruency: $F=6.712, p=0.010$ 


\section{Appendix E}

\section{Mean Response Time and Mean Percentage Error as a Function of Posture and Congruency from Experiment 1 conducted at Trent University}

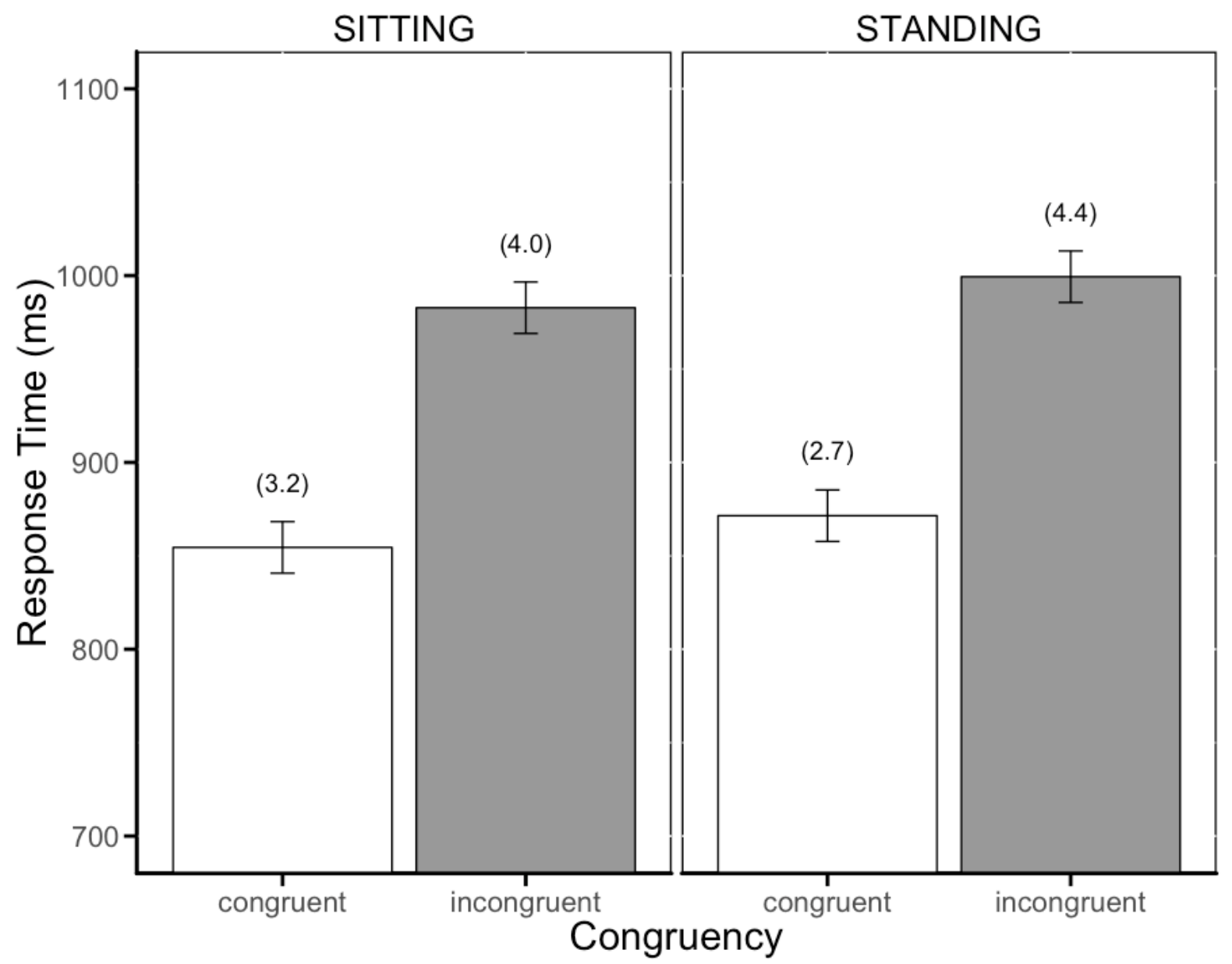

Figure 3. Mean Reaction Times and mean Percentage Errors as a function of Posture and Congruency from Trent Experiment 1. Error bars represent the 95\% confidence intervals are calculated using Loftus and Masson (1994). 


\section{Appendix F}

Mean Response Time and Mean Percentage Error as a Function of Posture and Congruency from Experiment 2 conducted at Trent University

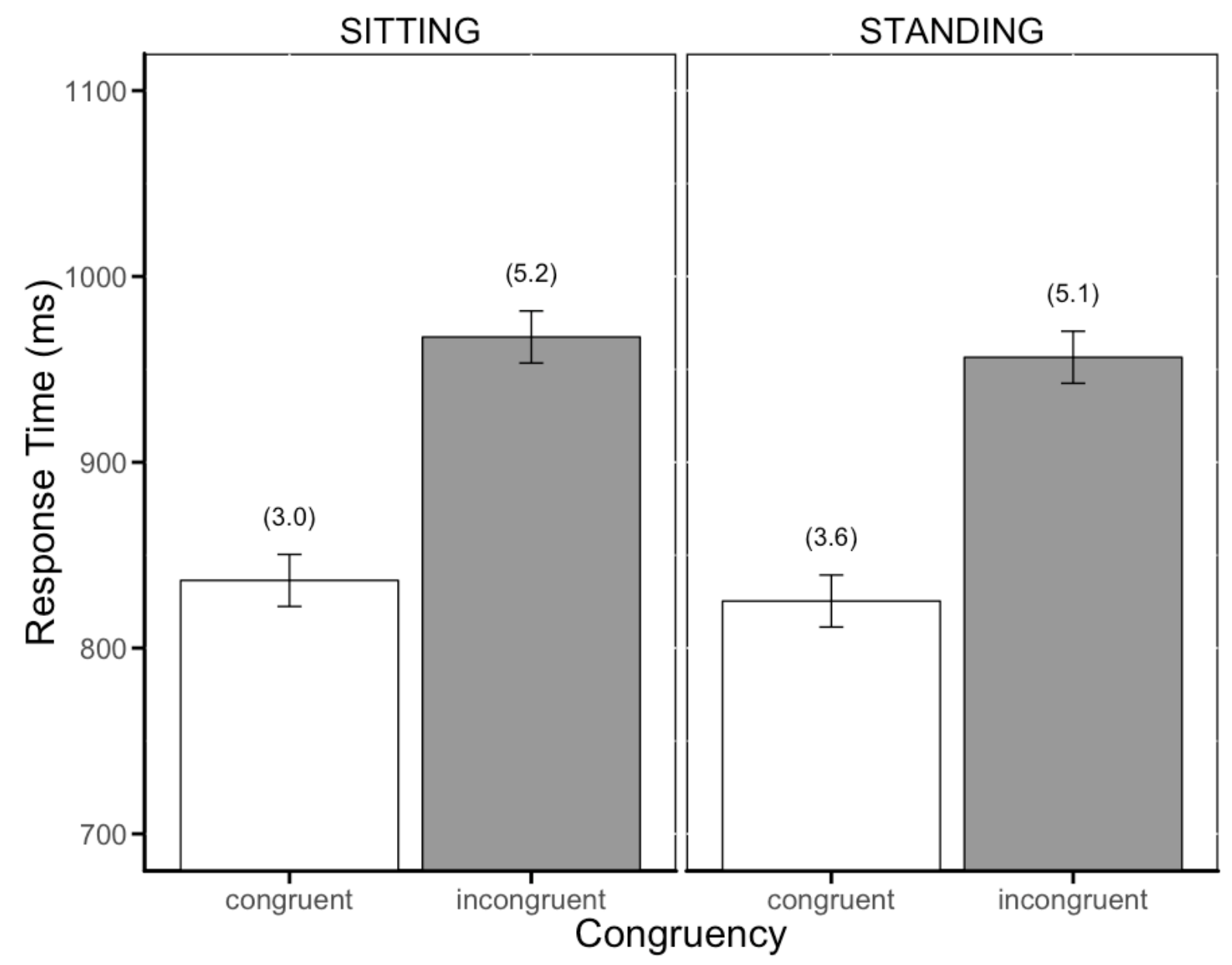

Figure 4. Mean Reaction Times and mean Percentage Errors as a function of Posture and

Congruency from Trent Experiment 2. Error bars represent the 95\% confidence intervals calculated using Loftus and Masson (1994). 